\title{
Imaginación moral y biografía
}

\author{
Imaginação moral e biografia \\ Moral imagination and biography \\ Jordi Gracia \\ Universidad de Barcelona, Barcelona, España
}

$\diamond$

\begin{abstract}
Resumen: Además de proponer en esquema las disparidades de las biografías de Cervantes, Ortega y Gasset y Ridruejo, el artículo defiende la condición de un requisito específico -la imaginación moral- como instrumento para recrear la complejidad interior de los sujetos biografiados, más allá de la fiabilidad empírica de la documentación pública y privada manejada.

Palabras clave: Biografía; Imaginación moral; Cervantes; Ortega; Ridruejo; Interpretación; Documentación
\end{abstract}

Resumo: Além de propor esquematicamente as disparidades das biografias de Cervantes, Ortega y Gasset e Ridruejo, o artigo defende a condição de um requisito específico - a imaginação moral - como instrumento para recriar a complexidade interior dos sujeitos biografados, para além da confiabilidade empírica da documentação pública e privada utilizada.

Palavras-chave: Biografia; Imaginação moral; Cervantes; Ortega; Ridruejo; Interpretação; Documentação

\begin{abstract}
Besides proposing in outline form the disparities of the biographies of Cervantes, Ortega y Gasset and Ridruejo, the article defends the condition of a specific requirement - the moral imagination - as an instrument to recreate the inner complexity of the subjects studied, beyond the empirical reliability of public and private documentation handled.
\end{abstract}

Keywords: Biography; Moral imagination; Cervantes; Ortega; Ridruejo; Interpretation; Documentation

A simple vista no hay semejanza alguna entre las vidas de tres personajes tan dispares como Miguel de Cervantes, José Ortega y Gasset y Dionisio Ridruejo. A los tres les he dedicado en los últimos años sendas biografías sin fabular paralelismos o conexiones de algún tipo entre los tres personajes ${ }^{1}$. Sin embargo, la observación de sus peripecias vitales por debajo de sus especificidades sí permite establecer alguna forma de relación analógica o semejanza de estructura en términos morales y de significación global. Reducidas a su esqueleto, las tres vidas descubren una imprevista ley

\footnotetext{
1 La vida rescatada de Dionisio Ridruejo (Anagrama, 2008), José Ortega y Gasset (Taurus, 2014) y Miguel de Cervantes. La conquista de la ironía (Taurus, 2016). Una versión anterior y ligeramente distinta de este trabajo apareció, a instancias de José-Carlos Mainer, en el número 99 del Boletín de la Institución Libre de Enseñanza (octubre de 2015), dedicado a Cervantes.
}

secreta en torno a la vivencia de la madurez: a dos de ellos (Cervantes y Ridruejo) el tiempo y la experiencia los reeducó rebelándolos contra sí mismos hasta hacerlos inequívocamente mejores, mientras al otro (Ortega) lo estropearon tanto el tiempo como la experiencia. Lo digo con deliberado simplismo porque por detrás de sus múltiples actividades y accidentes, se asienta en mi lectura de sus trayectorias la percepción de esa antítesis esencial. Ortega convirtó la potencia vitalista y contagiosa de su larga juventud en la caricatura agria de una autoridad saturada de su propia importancia. Cervantes y Ridruejo dibujan el trayecto contrario: con la madurez escapan de sus respectivas juventudes dogmáticas y cautivas de proyectos enajenantes y sólo después se hacen dueños de sí mismos, responsables conscientes de una inteligencia escarmentada, escéptica e irónica, aunque uno fuese sobre todo novelista y el otro fuese sobre todo ensayista. 
Todo esto es, por supuesto, una pobre exageración destinada a contrastar tres biografías: dos hicieron en la madurez su aprendizaje vital (Cervantes y Ridruejo); otro lo había aprendido ya todo desde el principio (Ortega), sin empatía con los demás, sin ensanchar sus puntos de vista, aplomado en verdades adivinadas muy tempranamente y ya desde entonces sumergido en una impermeable soberbia. Para nada prejuzga semejante diagnóstico la calidad de obras como La rebelión de las masas o la extraordinaria La idea de principio de Leibniz, la primera en torno a sus cuarenta años, la segunda cerca de los sesenta, en 1947. El diagnóstico atañe a la adivinación de un hombre progresivamente ensombrecido y casi traidor a sí mismo mientras en los otros dos vibra la conquista de un nuevo estadio ético e intelectual alumbrado con la experiencia de la madurez. La progresiva y acentuada filantropía compasiva de los dos primeros se trueca en la progresiva y autista misantropía desdeñosa del último.

De esta desconcertante disparidad nace también la reflexión sobre las condiciones del género o algunos de sus requisitos. La conquista de la ironía fue el subtítulo que adopté para la biografía de Cervantes, sin saber todavía hoy si existe una poética infalible para narrar la vida de alguien. Casi diría lo contrario: es evidente la pluralidad de medios legítimos para abordar una biografía compleja, a pesar de que a menudo esos métodos sean difíciles de conciliar entre sí. Por debajo de esas diferencias, sin embargo, sigue vigente la aspiración a un retrato diacrónico e integral, a la vez que sujeto a la elección de un eje o un motivo central capaz de vertebrarla o dotarla de sentido como peripecia cumplida o incumplida.

En mi caso, y para los tres autores, prevalece la fidelidad a una cronología fiablemente documentada como condición para contar una obra que crece y se expande con la propia vida y sus minucias, sin incurrir en falsas anticipaciones, sin profetizar lo que no hay razón ni datos para profetizar, sin avanzar ni falsificar la biografía presumiendo hechos o éxitos no sucedidos y quizá ni tan sólo imaginados. Mientras de Ortega y Gasset y Dionisio Ridruejo conservamos un arsenal abrumador de cartas íntimas y civiles, políticas y meditativas, de Miguel de Cervantes tenemos tres, a lo sumo cuatro cartas, y ninguna de ellas resuelve dudas sobre nada, aunque aporten datos sobre sus gestiones para encontrar empleo, para resolver conflictos con vecinos reticentes a entregar su trigo y para defender, en la tercera, la gestión administrativa de su superior como Proveedor General de las galeras, acusado de un uso abusivo del cargo. El vacío que suscitan es mucho mayor que el que cubren: lo grave no está en la invisibilidad de tantos tramos de la biografía de Cervantes sino en la ausencia de la voz privada, la gestualidad escrita y sentimental, la cadencia moral del sujeto.
Nada hay por ese lado de alguna entidad en Cervantes. A cambio, hay al menos dos fuentes nítidamente autobiográficas, además de los prólogos (tantas veces novelados) de sus obras: una es intensamente literaria y la otra es festiva y socarrona. La primera es la carta de auxilio que escribe, todavía preso en Argel en 1577, al importante secretario de Felipe II, Mateo Vázquez. La segunda es un viaje imaginario al monte Parnaso para evaluar la literatura de su tiempo, burlarse de ella y meter en medio un capítulo netamente confesional y autoreivindicativo en torno a sus 65 años. A lo sumo, pues, el lector dispone de dos autorretratos de Cervantes muy al principio y muy al final de su vida, y no demasiado explícito con respecto a sus sentimientos. Todo va contaminado, en el primer caso, de la urgencia de la libertad y, en el segundo, del desparpajo de la despedida.

Es verdad que quedan los prólogos. El de La Galatea es un texto próximo a las ejercicios retóricos de su tiempo y los otros dos que escribe, para el primer y el segundo Quijote, son tan tardíos como elaboradamente novelescos. Más cerca de sí mismo parece escribir, con un autorretrato incluido, en los dos restantes: el de las Novelas ejemplares y el de las Ocho comedias, mientras el más humorísitico y jovial de todos, y último, prologa su obra póstuma, Persiles y Sigismunda, en 1616, rozando los setenta años. Excepto en el primero, que es el más impersonal, los demás proceden de un autor algo más que adulto, emplazado sin duda en el tiempo de descuento. Incluso más: cuando remata el Quijote de 1604 Cervantes no tiene la menor pretensión de escribir una continuación y casi diría que lo termina convencido de que el segundo libro de su vida, ese primer Quijote de 1604, será también el último.

¿Hay alguna otra fuente relevante o mínimamente sustancial que aporte alguna luz o alguna pista valiosa? ¿Existe algo parecido a la dispersión fastuosa de testimonios orales, literarios, novelescos, epistolares, memorialísticos, cronísticos, periodísticos y fotográficos que cubren la biografía entera de Ortega para iluminar de tantos modos contradictorios al mismo escritor? ¿Hay algo semejante a la memoria ajena y el respeto que dejó tras su temprana muerte Ridruejo en 1975 en los libros y el articulismo y la vivencia de quienes lo conocieron? Es verdad que algo hay en el caso de Cervantes: unas líneas de una carta de Lope, otro pasaje suelto, otro más de Agustín de Rojas, un poema de Espinel, algunos poemas de otros amigos y poco más que cuente ni poco ni mucho sobre la existencia cotidiana de Cervantes al menos desde 1580. Para la etapa anterior, existen las declaraciones de varios compañeros sobre su conducta como hombre de armas entre 1571 y 1575 y en el cautiverio de Argel en los cinco años siguientes, y nada más. O casi: queda también la visión furtiva a la vida cotidiana de su familia 
que prestan los interrogatorios de un juez de Valladolid en 1605 , interesado por la muerte de un caballero a las puertas de la casa de Cervantes.

¿Puede suplirse de algún modo la información privada que no tenemos? ¿Hay rutas de acceso a ese esqueleto que he propuesto hace un instante y que emparenta al Cervantes de la madurez con el Ortega de los primeros tiempos y a la vez lo hermana con la honradez moral de Ridruejo en su tardía madurez? Las hay, pero son ajenas a las certidumbres y la literalidad de las fluctuaciones, matices, aprensiones y arrebatos que podemos desplegar hoy sobre Ortega y Ridruejo, sobre todo si el biógrafo aspira a hallar entre las líneas de sus ensayos y artículos, o su poesía y sus libros, las líneas de tensión que motivan sus cambios, sus inflexiones, sus euforias o sus agostamientos creativos.

En Cervantes todas esas modulaciones, incluso los destellos de su voz, están filtrados en la ficción dramática y narrativa mayor, en la novela de aventura marítima y exótica del Persiles o la aventura a pie de calle y en ruta campestre de tantas novelas breves, en los personajes y las voces de los narradores que nunca hablan por él, que nunca sienten por él, que nunca opinan como él. Sin embargo, el lector que ha vivido instalado en su casa o sumergido en su obra largamente y con la mente puesta en imaginárselo mientras lo lee en verso y prosa, atrapa certidumbres intuitivas en réplicas, diálogos y pasajes donde sabe que escucha a la persona y no a sus personajes. Negar la intensidad de esas intuiciones o desecharlas es hacerse trampas. Pero hipertrofiar esas intuiciones convirtiéndolas en dogma de fe es otra forma de indeseable egolatría autorial.

El recurso es arriesgado pero no temerario; sus propuestas son indemostrables pero no infundadas. Le llamo imaginación moral en la medida que asume la interiroización alta y cabal de la personalidad del biografiado, más allá de la capacidad o la posibilidad de probar esa imagen imaginaria de un sujeto real. Cuando a John Eliot Gardiner lo entrevistaron a propósito de su minuciosa biografía de Johan Sebastian Bach hizo una observación que hago mía (y que suprimí a última hora del manuscrito en marcha de mi Cervantes): "escuchar su música nos dice cómo era el hombre. ¿Puedo probarlo? No, pero me he expuesto mucho a él". Lo dijese con ese giro exculpatorio final o lo dijese de otro modo, Gardiner se asigna la autoridad para proponer la anatomía sentimental y moral de Bach más allá de su capacidad para probarla documentalmente. Gardiner defiende la coherencia y la consistencia interior de una perspectiva, la empatía con un sujeto y la predictibilidad aprendida ante sus conductas y reacciones a partir de la única fuente sustancial que existe sobre él (como sucede con Cervantes): la prolongada, atenta, intensa y activa exposición a su obra musical (o literaria, en el caso de Cervantes).

Yo no soy Gardiner, evidentemente, pero comparto la convicción de que la biografía es ese género literario atado al positivismo que sólo empieza a rendir como tal biografía un paso más allá del dato fáctico. Hace mucho tiempo que ha conquistado su autonomía como método de conocimiento y de comprensión del pasado, después de haber sido instrumento auxiliar de la historia. Pero su virtual aportación empieza sólo después del dominio de los datos probados -sean los que sean, más o menos ricos, públicos o privados-, y en ese tránsito a la interpretación es donde una biografía se juega su crédito y su solvencia; es desde ahí donde el biógrafo fabrica, encadena y anuda los datos y es donde empieza a operar con la imaginación moral que dota de sentido las notaciones de las partituras o las palabras de los relatos.

Es eso posiblemente lo que salva o condena una biografía, más allá de su irrenunciable fiabilidad documental. No se trata de aportar adicionalmente un complemento al dato o una sugerencia interpretativa; se trata de impregnar al relato de la visión integral y sucesiva del personaje. El instrumento insustituible es una variante de la imaginación que no inventa ni fabula pero sí proyecta y ajusta la intuición sobre lo que pudo ser real, y no sólo verosímil o probable. Quizá las razones de la insatisfacción que despiertan algunas biografías recientes en el ámbito español procedan precisamente de la ausencia de esa impregnación cabal para atrapar o para captar la secuencia íntima que hay detrás de una sucesión de hechos y de decisiones. José Lázaro aportó una información riquísima de datos y testigos en su biografía de Luis Martín-Santos pero renunció a ofrecer su lectura del personaje, en Vidas y muertes de Luis Martín-Santos (Tusquets, 2009). De la misma manera, José María Cuenca abordó con una semejante prevención su relato minuciosamente fáctico y documental de la biografía de Juan Marsé en Mientras llega la felicidad (Anagrama, 2015) y algo parecido cabe decir de la que J. Benito Fernández ha publicado en 2017 en torno a Rafael Sánchez Ferlosio (en Árdora Ediciones). En su mismo subtítulo, Apuntes para una biografía, va la renuncia explícita a ofrecer la versión integral, imaginada y consistente del personaje. En los tres casos las biografías han quedado más cerca de ser materiales para una biografía que biografías propiamente dichas: generosas con el futuro biógrafo por sus ingentes materiales inéditos e insustituibles, pero insuficientes y hasta mudas como relatos interpretativos de tres creadores.

Por contra, las tres biografías que he ensayado han actuado, sin duda más temerariamente, como propuestas de interpretación vital y crítica sometidas a las limitaciones de la información disponible para cada uno de ellos. En las tres era necesario hacer permeable la 
imaginación para instalar al lector en los sentimientos y la intimidad intencional de cada uno de ellos. Es verdad que la distancia histórica es un insuperable obstáculo para esas operaciones: mientras con Ortega y Ridruejo la discusión y casi el coloquio fueron posibles de forma natural, con Cervantes la distancia impuso una reserva y hasta una cautela que aleja la posibilidad de lo que Pierre Bourdieu llamó ilusión biográfica.

En el fondo, la operación es peligrosamente parecida a la del novelista que fabula sobre sus personajes desarrollando, exagerando, reprimiendo o ensanchando rasgos de su propia personalidad de escritor. De ella extrae la conjetura, fiable o equivocada, consecuente o imprevista, sobre la experiencia de vivir de sus personajes. El novelista carece de límites para esa operación, y en uno u otro personaje, o incluso en el relato de esta o aquella crisis, puede estar desnudándose como jamás lo haría en un texto autobiográfico, precisamente porque la ficción mantiene a salvo su intimidad (o la desnuda enmascarándola). Disfrazado de personaje se desnuda como persona y usa en la medida que sepa ese desaforado rencor que al autor le suscita la paz del campo, ese incontrolado afán de conquista que le despiertan las mujeres o esa ingobernable propensión a reñir a los demás. Da igual el motivo concreto, lo que importa es la impunidad con la que juega el novelista y el uso indisciplinado, reversible, corrupto, malintencionado, tramposo o fraudulento de su propias vivencias, ideas y sentimientos. Es la virtud de la ficción como ancho campo de la libertad.

Pero la similitud entre el novelista y el biógrafo termina ahí. En mi caso el límite es tan estricto como a veces enfadoso o laberíntico el método de escritura de al menos dos de esas biografías, a medida que encadeno citas literales y entrecomilladas en el propio discurso narativo. El freno para la fantasía está en ese anclaje del texto a la palabra exacta de los biografiados o sus testigos, y está en el empeño de hacerles decir a ellos, a través de sus palabras, su pensamiento y su experiencia. La aspiración más secreta del método en el fondo es desaforadamente inalcanzable: hallar el punto de fusión entre mi voz de narrador y la voz de ellos como confidentes y transmisores de sus sentimientos, de modo que el lector sienta que les escucha a ellos en sus vidas y no en las vidas que les impone el biógrafo.

Contra todas las apariencias, el biógrafo actúa con la misma libérrima condición imaginativa del novelista si aspira a rastrear el movimiento interior de una intimidad y no se satisface con la crónica de los hechos y las obras. Contra todas las apariencias, uno y otro, el novelista de ficción y el biógrafo, comparten la disposición a imaginar y encandenar causas íntimas y externas, movimientos anímicos y momentos esenciales. Pero mientras al novelista nada le sujeta a una verdad necesaria, el biógrafo proyecta su imaginación sobre la disciplina de los textos y hechos de que dispone, y en esa masa de información planifica, ordena y selecciona las palabras que mejor recrean al biografiado: no a su mejor yo, sino al yo múltiple que fue entre varios sucesivos, contradictorios y simultáneos. De nuevo vale aquí una comparación musical: Leonard Bernstein explicó a menudo el hecho desnudo de que las partituras originales de Bach carecían de notación alguna sobre el modo de interpretar su música. La única vía que quedaba al intérprete moderno de sus composiciones consistía en interiorizar y comprender la integridad de la pieza, asumirla como tal en su estructura y su desarrollo para decidir por su cuenta, desde esa comprensión única, el lugar de los énfasis, el fraseo o el tempo que pide la pieza ya interpretada.

La dependencia de la cronología más precisa posible es así inexcusable para que logros y fracasos de un autor no condicionen retroactivamente un relato donde ni el logro ni el fracaso han llegado todavía. Puede ser ese el mejor mecanismo para sofrenar la tentación de esmaltar de anacronismos y profecías las biografías, como si a cada paso pudiese ilustrarse con una obra futura la vida precedente, o como si a cada paso un dato o un detalle valiese como profecía del futuro. Ha sido mi requisito íntimo más estricto para que el texto no se contagie de lo que sucederá (pero no ha sucedido aun) y para respetar por tanto no sólo la veracidad de la historia sino incluso las condiciones de credibilidad para entender al creador: ni Cervantes sabía de joven que sería el genio que inventó la novela moderna con el Quijote ni Ortega adivinó la plenitud europea de su nombradía filosófica (ni siquiera adivinó su consagración con treinta años en Buenos Aires: le asaltó allí) ni Ridruejo cultivó al socialdemócrata de temple escéptico e irónico en los fervores fascistas de sus veinte años.

La lealtad empírica a ese despliegue moroso es la condición de veracidad de una biografía para no deformar interesadamente una vida destinada teleológicamente a cumplirse en un futuro prescrito. Leer a Cervantes en La Galatea como si ahí estuviese el futuro autor del Quijote difumina la intención real de ese libro como tarjeta pública de presentación para el mercado de secretarios y escribientes de la corte. Para el biógrafo es tan disparatado leerla a la luz del Quijote como negar a Cervantes el tránsito y la maduración que precisamente le apartará del mundo moral de la bucólica artificiosa y quebradiza y lo empapará muchos años después de la parsimonia irónica y dialogada de una novela nueva y revolucionaria. El prurito de lealtad a esa cronología empírica obliga entonces, como me ha sucedido a mí, a aplazar la mención del Quijote (al margen del prólogo) hasta más allá de las doscientas primeras páginas de la biografía porque Cervantes no es autor del Quijote hasta después de sus cincuenta años. 
De hecho, ni siquiera sabe Cervantes mientras redacta su cuento sobre un señor que sale a caballo por el patio de atrás de su casa que dentro de ese cuento va a descubrir la semilla de una historia revolucionaria sobre la cabeza más despejada del mundo. Contar su vida como si supiese desde siempre que inventará el Quijote deforma la exposición misma de las condiciones que hicieron posible semejante invención: rebaja a cumplimiento fatal lo que fue en realidad una experiencia imprevista y tentativamente explicable.

\section{Referencias}

CUENCA, José María. Mientras llega la felicidad. Una biografía de Juan Marsé. Barcelona: Anagrama, 2015.
GRACIA, Jordi. La vida rescatada de Dionisio Ridruejo. Barcelona: Anagrama, 2008.

GRACIA, Jordi. José Ortega y Gasset. Madrid: Taurus, 2014.

GRACIA, Jordi. Miguel de Cervantes. La conquista de la ironía. Madrid: Taurus, 2016.

LÁZARO, José. Vidas y muertes de Luis Martin-Santos. Barcelona: Tusquets, 2009.

FERNÁNDEZ, J. Benito. El incógnito Rafael Sánchez Ferlosio. Apuntes para una biografía. Madrid: Árdora Ediciones, 2017.

Recebido: 07/02/2018

Aprovado: 07/02/2018

Contato:

Jordi Gracia <jotagracia@hotmail.com>

ORCID: <https://orcid.org/0000-0002-7470-6933> 